Print ISSN: 2288-4637 / Online ISSN 2288-4645

doi:10.13106/jafeb.2019.vol6.no3.103

\title{
Monetary Policy Transmission during Multiple Indicator Regime: A Case of India
}

\author{
Madhvi SETHI ${ }^{1}$, Saina BABY ${ }^{2}$, Vandita DAR $^{3}$ \\ Received: June 17, 2019 Revised: June 27, 2019 Accepted: July 13, 2019
}

\begin{abstract}
The effectiveness of monetary policy critically depends upon how well the transmission mechanism functions, so that the desired impact on output and inflation is achieved. The purpose of this paper is to study the transmission mechanism of monetary policy by analyzing the impact on inflation and output during multiple indicator regime (1998-99 to 2014) in an emerging economy-India. The Inflation Targeting Regime is also briefly outlined alongwith the impact on output and inflation. Using quarterly data for the period 1997 to 2017 , the paper uses weighted average call money market rate as a proxy for the policy rate and evaluates the strength of the interest rate channel. We use a conventional Structural vector auto regression (SVAR) methodology to evaluate the efficacy and show the impluse response functions. Our results find that changes in the policy rate impact output growth steeply with a lag of about two quarters and the impact on inflation is maximized after three quarters. The study concludes that the monetary policy in India has a significant impact on output and inflation in the short-to-medium-run. After the policy shock, the fall in the output growth rate is of greater magnitude than the fall in inflation.
\end{abstract}

Keywords: Monetary Policy Framework, Interest Rates, Regimes, Structural Vector Auto Regression, Impulse Response Function

JEL Classification Code: E52, E49, E42, C59

\section{Introduction}

Most of the early monetary theories try to establish a relationship between money supply and inflation. The earliest of these was the quantity theory of money by Jean Bodin in 16th century. According to his theory the main reason for the European inflation during 1500 to 1625 was an increase in money supply, i.e. increase in the inflow of

1 First Author and Corresponding Author. Professor, Symbiosis Institute of Business Management Bangalore, Symbiosis International (Deemed University) Pune, India [Postal Address: 95/1, 95/2 Electronic City Phase 1, Hosur Road, Bangalore 560100, India]. Email: madhvi.sethi@sibm.edu.in

2 Assistant Professor, Symbiosis Institute of Business Management Bangalore, Symbiosis International (Deemed University) Pune, India. Email: saina.b@sibm.edu.in

3 Adjunct Faculty, Symbiosis Institute of Business Management Bangalore, Symbiosis International (Deemed University) Pune, India. Email: vandita.dar@sibm.edu.in

(c) Copyright: Korean Distribution Science Association (KODISA)

This Commercial License (https://creativecommons.org/licenses/by-nc/4.0/) which permits unrestricted no commercial use, distribution, and reproduction in any medium, provided the original work is properly cited. gold and silver to Europe from America. The proportional relationship between money supply and price level was originated by David Hume. "If we consider any one kingdom by itself, it is evident, that the greater or less plenty of money is of no consequence; since the prices of commodities are always proportioned to the plenty of money."(Hume, 1752a). The direct and proportional relationship between money supply and inflation was formally expressed as an equation by Irving Fischer popularly known as the equation of exchange (Fisher, 1911).

$$
\mathrm{MV}=\mathrm{PT}
$$

$M$ is the total nominal amount of money supply in circulation in an economy.

$\mathrm{V}$ is the velocity of money, that is, the average frequency with which a unit of money is spent.

$P$ is the price level and

$\mathrm{T}$ is volume of transactions

As per the assumptions of this model $\mathrm{V}$ and $\mathrm{T}$ are constants and therefore any change in $M$ leads to proportional change in $\mathrm{P}$. 
The classical theorists believed in neutrality of money, that is, changes in money supply can affect only the nominal variables like price and not the real variables like employment or output. Keynes (1932) challenged this money neutrality concept of classical theorists by saying that changes in money supply can influence the real variables also in the economy along with nominal variables. When classical economists proposed a direct and immediate effect of money supply on prices, Keynes proposed an indirect link between money supply and price level. He brought in interest rate as a mediating variable to explain this linkage. According to Keynesian theory of money, when the money supply increases, interest rate goes down which in turn stimulates investment and employment in an economy. As the economy expands the demand for factors of production increases and that pushes up the cost of production and then the prices. Though Keynes realized the effectiveness of expansionary monetary policy as a counter cyclical measure, his faith in fiscal policy was stronger due to the belief in working of multiplier effect.

The failure of Keynesian economics to tackle the stagflation of 1970s brought the monetary policy effectiveness related debate back into action. Milton Friedman of the Chicago school was the champion of school of thought called monetarism. According to him "inflation is always and everywhere a monetary phenomenon" and monetary policy is very effective in counteracting inflationary pressures in an economy.

Over the years, monetary policy has been formulated with the purpose of achieving the twin objectives of economic growth and price stability through the successful working of the transmission mechanism. Monetary policy induced changes in the nominal variables are expected to impact the real economic indicators like GDP and inflation.

In India, the central bank, Reserve Bank of India (RBI), had started using monetary policy instruments extensively from the 1950s. The evolution of RBI's monetary policy has been divided into four distinct frameworks. Pre- monetary targeting framework existed during 1947 to 1985 . Then RBI came up with a specific monetary targeting framework during 1985 to 1998 by defining exact money supply (M3) growth target to achieve the monetary policy objectives.

RBI's monetary policy strategies have undergone substantial transformation in the last 70 years. The success of each monetary policy framework can be assessed by comparing the impact of monetary policy changes on various economic performance indicators. Monetary policy works in an economy through the monetary transmission mechanism. The monetary transmission mechanism describes how policy-induced changes in the nominal money stock (money supply) or the short-term nominal interest rate impact real variables such as aggregate output and employment.

Monetary policy framework provides an outline for achieving the task mandated to the monetary authority in a country. Even though the monetary policy in India has undergone substantial transformation over the years, the task mandated to $\mathrm{RBI}$ remained unchanged. As per the RBI act 1934 , the task mandated to $\mathrm{RBI}$ was “...to regulate the issue of Bank Notes and keeping of reserves with a view to securing monetary stability in India and generally to operate the currency and credit system of the country to its advantage." A general interpretation of this statement reveals that maintaining price stability along with stable economic growth is the main mandate of RBI's monetary policy. Because of the conflicting nature of these two objectives, a trade off or balancing is required while formulating monetary policy decisions. The relative importance given to these objectives and the tools used to achieve these objectives vary depending on the economic conditions existing in a country. RBI has been experimenting with various monetary policy frameworks in the last 70 years. These frameworks can be classified under four major categories.

- Pre-monetary targeting (Independence to 1984-85)

- Monetary Targeting (MT)- 1984-85 to 1997-98

- Multiple Indicators approach (MIA) - 1998-99 to 2014

- Inflation Targeting (IT) - From 2015 Onwards

\subsection{Pre-monetary Targeting (Independence to 1984-85)}

Till 1970s, inflation was mainly due to agricultural failures. Therefore, RBI's agenda was selective bank credit management and ensuring flow of credit to boost agricultural production. In 1970s inflation saw an upward trend because of increase in money supply which rose to finance rise in government expenditure. Inflation also rose because of the oil shocks in 1974 and 1979 which shot up prices of oil in world markets.

\subsection{Monetary Targeting (MT, 1984-85 to 1997-98)}

By early 1980s, there was some consensus in RBI that inflation was increasing because of a surge in money supply. Agriculture and oil shocks could not raise inflation permanently. It was a sustained rise in money supply that led to increase in inflation. This led to RBI's monetary targeting framework in which RBI started targeting money supply. Under this RBI made estimation for money supply 
for a given year and tried to keep money supply around the estimated levels.

\subsection{Multiple Indicators Approach (MI, 1998-99 to 2014 Onwards)}

After reforms in 1991, it was difficult to look at the relationship between money supply and inflation. Financial liberalization gave birth to more innovative financial products. Earlier RBI could monitor money supply as banks were the only financial intermediaries, but things changed after liberalization. As non-banking financial corporations grew, monitoring money supply and thus inflation became difficult. Hence, RBI adopted the multiple indicators approach which looked at variety of economic indicators to watch impact on inflation and economic growth.

\subsection{Inflation Targeting (IT) - (From 2015 Onwards)}

In 2013, the Governor of the Reserve Bank of India Dr. Raghuram Rajan announced a shift in policy anchor considering flexible inflation targeting. This presents the policy makers' stance of not tolerating inflation as a deterring factor in the economy any more. This has brought about two most important structural changes in the economy, price stability is now primary policy objective and the nominal policy anchor is CPI.

The efficacy of the monetary policy transmission mechanism is judged by the impact of the induced changes in monetary policy parameters on real economic indicators such as GDP and inflation. Through this paper we make an attempt to study the transmission mechanism of monetary policy by analyzing the trends in inflation and output during multiple indicator regime. The Inflation Targeting Regime is also briefly outlined along with the impact on output and inflation.

\subsection{Monetary Policy Transmission Mechanism: The Channels}

There are four channels of monetary policy transmission to the real economy:

\subsubsection{The Interest Rate Channel}

Nominal short-term policy interest rate changes lead to changes in the short-term real interest rate. These movements in real interest rates are expected to impact the decisions of economic agents- business investment decisions are impacted by changes in the cost of capital, while consumption gets impacted by changes in deposit interest rates and treasury bonds yields.

\subsubsection{The Credit or Loan Supply Channel}

The credit channel operates through two channels:

Bank Lending Channel: Tight monetary policy implemented through higher reserve requirements or purchases of commercial bank reserve assets by the central bank, results in lower usable reserve assets at commercial banks, and also lower deposits at commercial banks as economic activity is unfavourably impacted. This depresses the bank loan supply, especially to small firms, causing adverse impacts on investment activity.

Balance Sheet Channel: A tight monetary policy implemented through higher interest rates reduces cashflows, and has a negative effect on the prices of financial assets, which could be used as collateral, resulting in lower net worth of firms. This results in lower investment spending by firms. Weaker balance sheets also create moral hazard and adverse selection problems, and make funds inaccessible for borrowing firms.

\subsubsection{The Exchange Rate Channel}

An increase in the interest with a flexible exchange rate regime and an open capital account, makes deposits in domestic currency more attractive than those in foreign currencies, leading to an exchange rate appreciation. However, expectations about foreign and domestic interest rates, inflation and policy changes are predominant in the operation of this channel. The appreciation or depreciation of the exchange rate affects GDP through the change in the relative prices of exports and imports.

\subsubsection{The Asset Price Channel}

Contractionary monetary policy can have an adverse impact on financial assets and real estate, making them unattractive compared to bonds. With a rise in long-term interest rates, value of housing and financial assets fall, depressing the financial wealth of households and adversely impacting consumption. Lower values of financial assets reduce the market value of firms relative to the replacement cost of capital (Tobin's q), adversely affecting investment.

In this paper, we analyse the multiple indicator approach and inflation targeting approach for India by looking at inflation and output. Our results show that changes in the policy rate impact output growth steeply with a lag of about two quarters and the impact on inflation is maximized after three quarters. The results seem to suggest that the impact 
of a policy rate shock is much more evident on output growth rather than inflation.

This paper is divided into five sections. Section one deals with the introduction of transmission mechanism. Section two covers the review of literature, section three of the paper presents the data and methodology. Section four presents the analysis with discussion of findings and section five provides the conclusion.

\section{Literature Review}

Monetary policy transmission has been one of the most researched areas of monetary policy since it has implications for the real economy, especially aggregate demand. Romer and Romer (1990), incorporated credit market imperfections in monetary policy transmission, and showed that the impact of monetary policy on interest rates occurred primarily through the liabilities side (transaction balances) rather than the assets side (lending) of banks' balance sheets. Boivin, Kiley, and Mishkin (2010) studied the evolution of the monetary transmission and its channels over a period of 30 years till 2010 for the US and found that the neoclassical channels like the interest rate remain strong, while non-neoclassical channels such as bank credit played a much lesser role in monetary transmission. These variables appeared more as shocks rather than an endogenous transmission mechanism. Endut, Morley and Tien's (2018) study covering a 50-year period suggested equally important roles for bank-lending and the interest rate channels till about the 1980s, after which interest rate emerged as the singularly important transmission channel, which explained much of the unconventional monetary policy actions in the US post the 2008 financial crisis. In another study spanning 1984-2005, Boivin and Giannoni (2008) found scant evidence in support of the role of global factors in monetary transmission, however global forces have been somewhat evident after 2000, reducing the persistence of response to monetary policy changes. Bernanke and Blinder (1992) found that while the Federal Funds rate was an effective predictor of real economic variables, monetary policy worked through both credit and the interest rate channels. On similar lines, Bernanke and Gertler (1995) focused attention on the credit channel of monetary policy especially the balance sheet and bank lending channels, suggesting that the response of inventories and investments was much better explained through them rather than the movement in interest rates.

Several studies exist with respect to transmission mechanism of different countries. Jannsen, Wolters, and Potjagailo (2015) in their cross-country study of 20 developed economies brought out the differences in the functioning of the monetary transmission channels during crises and non-crises, their evidence showing that such transmission worked much more effectively during crises. Even during crisis, the transmission to output and inflation happened much faster and better during the acute phase, while the impact during the recovery phase was much smaller.

He's (2017) analysis of US Fed's monetary policy effectiveness for the period 1871-2013 highlighted that the modern-day balanced approach of the Fed on both inflation and output had proved to be more effective than the goldstandard era approach that was biased towards output growth. Fujiwara (2004) suggested that for Japan monetary transmission predominantly happened through the interest rate channel via investment as is the case with the Euro Area, unlike the US where this channel operated more through consumption and intertemporal substitution.

In their study, Mishra and Montiel (2012) and Mishra and Montiel (2013) found weak monetary transmission in developing countries, as also significant disparities in the response of bank lending rates to monetary policy shocks across countries. Looking at effective and expected interest rates in Brazil, Moreira, Chaiboonsri and Chaitip (2014) found that the Central Bank can effectively smooth adjustments in short-term interest rates. Their evidence also showed that Brazilian monetary policy was efficient and transparent. Silva, Brasil and Moreira (2016) found that Brazil's monetary policy inertia was followed by positive output gaps that caused inflation to spurt in the period 20052013. Their results suggested that monetary policy gradualism had to be better calibrated with its inflationtargeting approach. Lerskullawat (2018) used quarterly bank level panel data from 1992-2011 for Thailand and the findings revealed the significance of the bank lending channel in monetary policy. Wulandari (2012) studied Indonesian monetary policy transmission mechanisms and showed that while the interest rate channel was important for maintaining price stability, the bank lending channel was successful in promoting growth. Vo and Nguyen (2017) used monthly data from Vietnam and found the existence of an interest rate channel, while the exchange rate and the asset price channels seemed non-existent. Ghazanchyan (2014) explored monetary transmission in Sri Lanka where the interest rate channel emerged the strongest followed by the bank lending channel, while the exchange rate channel was muted.

Bredin and O'Reilly (2001) studied monetary transmission in Ireland using quarterly data from 1980-96 when the country was a member of the European Monetary System (EMS). They found that a monetary contraction led to a fall in prices and growth and an immediate exchange rate appreciation followed by depreciation, due to its 
commitment to a quasi-fixed exchange rate. With the limited scope of an independent monetary policy during this period, while the impact on macroeconomic variables corroborated existing theories, it was very small. Ramlogan (2004) studied the transmission mechanism in four Caribbean countries using quarterly data for the period 1970-2000 and their findings pointed to the importance of the credit and the exchange rate channels in monetary transmission in these countries, rather than the money channel.

The literature on the efficacy of monetary policy transmission mechanism in India is summarised well by Mishra, Montiel, and Sengupta (2016). They observed a significant increase in bank lending rates as a result of tightening the monetary policy. The transmission to lending rates was only partial and exchange rate effects were weak. They found no significant effects on real output or the inflation rate. Mohan (2007) elaborated the evolution of the operational framework of monetary policy in India, instruments used for liquidity management, and reforms. He suggested that monetary policy was by and large successful in meeting its critical twin objectives of price stability with growth especially in the post-reforms period, and the interest rate pass-through also saw an improvement in the post-reforms era. He also noted that while the changes in policy rates were quickly transmitted through the money market rates as well as in government bond yields, lending and deposits rates of banks tended to be plagued with a degree of downward inflexibility, owing to administered interest rates.

Volatility in the international economy, financial crises such as the Asian currency crisis, increasing trade openness, global disinflation, shifts in the monetary policy operating framework from a monetary targeting to a multiple indicator approach all impeded monetary transmission. Khundrakpam and Jain (2012) studied the effectiveness of all the four monetary transmission channels in India. They also considered OECD GDP and gross portfolio inflows as exogenous variables, and found that the impact of external variables prolonged the impact of monetary policy shocks on GDP growth and inflation. Interest rate, asset price and credit channel emerged as important while exchange rate channel was weak. The interest rate channel accounted for almost half of the total impact of monetary shock to GDP growth and about one third of total impact on inflation. AlMashat (2003) used the overnight call money rate to capture monetary policy transmission and suggested a strengthening of the interest rate and exchange rate channels in monetary policy transmission, while bank lending channel seemed ineffective due to priority lending commitments. The inclusion of exchange rate in the model further amplified the impact of a monetary policy shock on macroeconomic variables.
Mohanty (2012) focused on the interest rate channel, studying policy rate changes through to their effects on output and inflation. He found that policy rate increases had a negative effect on output growth with a lag of two quarters as well as a moderating impact on inflation with a lag of three quarters, with both effects persisting for eight to ten quarters. His study highlighted the role of interest rates as an effective monetary policy instrument.

Singh (2011) explored the pass-through from the policy rate to a variety of short and long term market interest rates, finding significant contemporaneous pass-through under deficit liquidity conditions along with significant lagged effects. Das (2015) found significant and gradual, passthrough of policy rate changes to bank interest rates in India in her study period from March 2002 to October 2014. Suggesting an asymmetric transmission, the lending rate adjusted more quickly to monetary tightening than to loosening, just as deposit rates adjusted downwards to loosening but not upward to monetary tightening.

Khundrakpam (2011) showed that the credit channel of monetary transmission was significant and robust in the post-Liquidity Adjustment Facility (LAF) period. Using a VAR model, Sengupta (2014) found a structural break in transmission corresponding to the introduction of the Liquidity Adjustment Facility (LAF) in 2000. While the bank lending channel had remained significant since the introduction of the LAF, the interest rate and asset price channels had become stronger, while the exchange rate channel, despite being weak showed a slight improvement in the post-LAF period.

Using quarterly data from 1996 to 2007, Aleem (2010) found that an unanticipated increase in the call money rate led to a decline in GDP in third quarter and showed a V shaped response. Prices also declined after the fall in GDP in response to a positive overnight call money rate shock and recovered after third quarter. This effect disappeared when exogenous variables were added and monetary policy shock had temporary effects on the call money rate. Prime lending rates responded immediately to a positive call money rate shock, and converged towards the baseline after the second quarter. Quantity of bank loans to the commercial sector decreased initially in response to a monetary policy tightening and then recovered after the third quarter. Prices and GDP showed a similar decline, bottoming out in third quarter. Bhattacharya, Patnaik, and Shah (2011) suggested a weak monetary transmission mechanism in India, with interest rate changes not having a direct impact on aggregate demand and output. There was evidence of statistically significant, though incomplete exchange rate pass-through.

Mallick (2009) suggested that a contractionary monetary policy shock was associated with a statistically significant 
reduction in real output, but monetary policy shocks accounted only for an insignificant part of the forecast error variance in real output. Singh and Kalirajan (2007) emphasized the significance of interest rate as the major policy variable for conducting monetary policy in post reform India. Salunkhe and Patnaik (2017) estimated the causal relationship between monetary policy proxied by the weighted average call money rate and its performance indicators; output and inflation. They found that a policy rate increase resulted in a fall in output after four months, and then dissipated gradually over a period of seven to eight months. The impact of the policy shock on inflation occured only after five months, when inflation fell and this persisted for two to three months. Prabu and Ray (2019) studied the monetary transmission to different segments of the financial markets in India and showed that the money and bond markets experienced a faster and more efficient transmission compared to the foreign exchange and the stock markets that had weak transmission effects.

Our objective in this paper is to study the transmission mechanism of monetary policy in India by analyzing the trends in inflation and output during multiple indicator regime (1998-2014).

A natural disadvantage that confronts researchers in analysing monetary policy transmission in India is that such an analysis needs high frequency data and quarterly GDP data for the country was available only from 1996 onwards. While some studies on transmission mechanism have used monthly data on industrial production or the Index of Industrial Production (IIP) to overcome this problem, IIP remains a very weak proxy for quantifying overall economic growth. Real GDP is far superior to IIP as a measure of economic growth. Earlier studies that have used IIP to study the transmission effects of monetary policy are by Pandit, Mittal, Roy, and Ghosh (2006), Bhattacharya, Patnaik, and Shah (2011), Mishra, Montiel, and Sengupta (2016) and Salunkhe and Patnaik (2017). While quarterly GDP series have been used by Kapur and Behera (2012), Khundrakpam and Jain (2012), Mohanty (2012), Aleem (2010), and Al-Mashat (2003) to study the efficacy of monetary transmission, such studies remain restricted to shorter periods.

We have extended the period of our monetary transmission study to cover the entire expanse of the multiple indicator regime with quarterly GDP growth as one of the impact variables. Also almost all of the aforementioned studies use the Wholesale Price Index (WPI) as a proxy for the price variable, barring Mishra, Montiel, and Sengupta (2016) and Salunkhe and Patnaik (2017), who consider the Consumer Price Index (CPI). Our study also incorporates the more realistic and representative CPI as the price variable. We expect that the use of more accurate proxies like Real GDP and CPI will improve the accuracy our results. We have also tried to do a monetary regime based study with the objective of identifying the strengths of the multiple indicator regime in terms of its impact on the twin goals of monetary policy. The outcomes of this study will provide insights dealing with monetary policy related strategies. While the study in its existing form is restricted to the multiple indicator regime and the interest rate channel, we intend to do a similar analysis with the inflation targeting regime.

Considering the multiple indicator regime exclusively along with incorporating quarterly GDP as a proxy for output and quarterly $\mathrm{CPI}$ as a proxy for inflation are the unique aspects of this study.

\section{Data and Methodology}

Strength of various channels of the monetary transmission mechanism in India has been examined using a conventional structural VAR methodology (Sims, 1980). We have used quarterly data for the period 1997 to 2017 for the purpose of our analysis. We use the weighted average call money market rate as a proxy for the policy rate and evaluate the strength of the interest rate channel by comparing the impulse responses of inflation and economic growth to policy shock (Table 1 ).

Table 1: Data Sources for the Variables used in the Study

\begin{tabular}{|l|l|}
\hline \multicolumn{1}{|c|}{ Variable Name } & \multicolumn{1}{c|}{ Source of Data } \\
\hline $\begin{array}{l}\text { Real GDP Growth } \\
\text { Rate(YoY) }\end{array}$ & $\begin{array}{l}\text { Government of India, Ministry of } \\
\text { Statistics and Programme } \\
\text { Implementation (MOSPI) }\end{array}$ \\
\hline CPI Quarterly rate & $\begin{array}{l}\text { Government of India, Ministry of } \\
\text { Statistics and Programme } \\
\text { Implementation (MOSPI) }\end{array}$ \\
\hline $\begin{array}{l}\text { Weighted Average call } \\
\text { money market rate }\end{array}$ & $\begin{array}{l}\text { Reserve Bank of India's Data } \\
\text { Warehouse }\end{array}$ \\
\hline
\end{tabular}

The Vector Auto-Regression (VAR) methodology proposed by Sims (1980) is a widely accepted standardized tool for monetary policy analysis. The present study uses the Structural Vector Autoregression (SVAR) model to estimate the underlying structural relationship between the policy rate, inflation, and output growth on the one hand, and the output growth and inflation on the other. While VAR model specifications are atheoretical, without much scope of an economic interpretation of their results, SVAR models transform the reduced form models into a system of structural equations which can then account for economic interpretation through the impulse responses that they yield. Our SVAR model consisting of GDP growth rate, inflation, and the policy rate (proxied by call rate) is presented below. 


$$
\left[\begin{array}{l}
e_{1 t}^{\text {Oupput }} \\
e_{2 t}^{\text {hylation }} \\
e_{3 t}^{\text {call }}
\end{array}\right]=\left[\begin{array}{ccc}
1 & 0 & 0 \\
a_{21} & 1 & 0 \\
a_{31} & a_{32} & 1
\end{array}\right]\left[\begin{array}{l}
\varepsilon_{1 t}^{\text {Ouput }} \\
\varepsilon_{2 t}^{\text {hrflation }} \\
\varepsilon_{3 t}^{\text {Call }}
\end{array}\right]
$$

\section{Results and Discussion}

Multiple Indicator transmission channel of monetary policy prevailed from 1998-99 to 2014. It can be asserted that monetary policy has been successful in meeting its twin objective of maintaining low inflation with high GDP growth rate in the period post liberalization. During this period India shifted from monetary targeting to multiple indicator approach. Table 2 (a) and (b) provide the descriptive statistics of the data we have used.

Table 2 (a): Descriptive Statistics of CPI, Real GDP growth rate and weighted average call money market rate

\begin{tabular}{|l|c|c|c|}
\hline & $\begin{array}{c}\text { CPI } \\
\text { Quarterly } \\
\text { rate }\end{array}$ & $\begin{array}{c}\text { Real GDP } \\
\text { Growth } \\
\text { Rate(YoY) }\end{array}$ & $\begin{array}{c}\text { Weighted Average } \\
\text { call money market } \\
\text { rate }\end{array}$ \\
\hline Mean & 7.00 & 6.99 & 6.99 \\
\hline Median & 6.40 & 6.96 & 7.24 \\
\hline $\begin{array}{l}\text { Standard } \\
\text { Deviation }\end{array}$ & 3.43 & 2.57 & 2.09 \\
\hline Minimum & 0.47 & 0.24 & 2.42 \\
\hline Maximum & 16.34 & 13.26 & 14.07 \\
\hline Count & 71.00 & 71.00 & 71.00 \\
\hline
\end{tabular}

Table 2(b): Correlation and Covariance of Variables

\begin{tabular}{|c|c|c|}
\hline & GDP and CPI & Call market rate and CPI \\
\hline Correlation & 0.124 & 0.004 \\
\hline Covariance & 1.093 & 0.031 \\
\hline
\end{tabular}

In this span of 25 years, average CPI was $6.99 \%$. The trend of CPI can be seen in Figure1. Since early 1990s, world has seen a declining trend in inflation, and India since late 1990s. It was as low as $0.47 \%$ in 1999 whereas it was significantly higher in the period from 2008 to 2014. Structural reforms in India since the early 1990s along with improved monetary-fiscal interface and development in the government securities market enabled better money supply management from the second half of the 1990s onwards. It is encouraging to note that despite record high international crude oil prices, inflation remained low and inflation expectations were also stable.

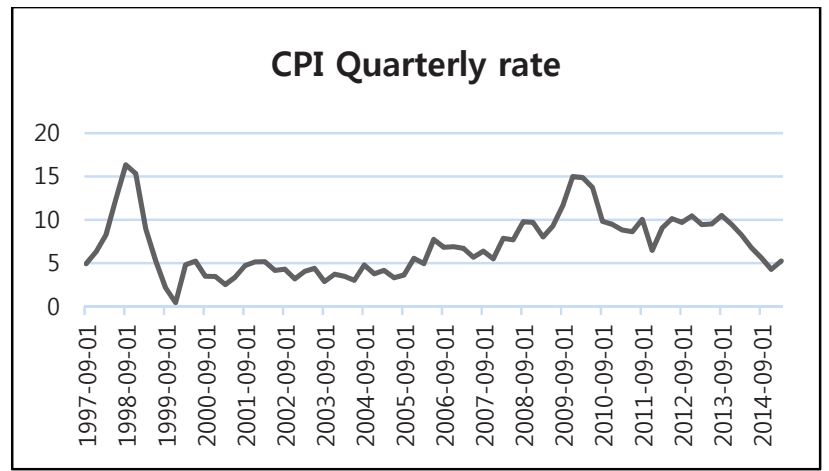

Figure 1: Trend of CPI during multiple indicator regime

From late 2007, US economy followed the path of Quantitative Easing, meaning pumping in more liquidity into the economy. As the US interest rates were too low, money started flowing into Indian economy were investors were getting good returns due to higher interest rates. This made a case of imported inflation in India in the period from 2008 to 2014.

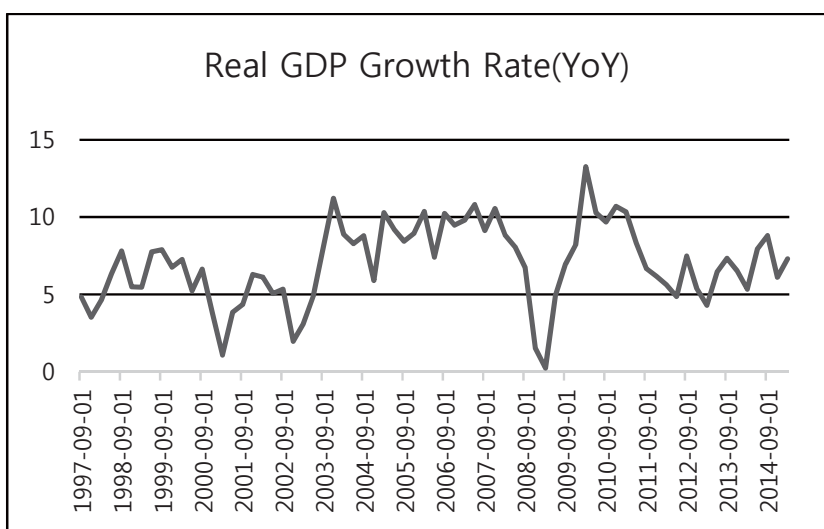

Figure 2: Trend of Real GDP growth rate during multiple indicator regime

A quick look into the time series plot (Figure 2) of the real GDP growth rate too provides essential insights. The average GDP growth over the sample period of September 1997 to March 2015 is $6.98 \%$. As the multiple indicator approach was adopted by RBI few years after India opened for private investments, the direct impact of the changed policies was seen in the improved growth rate. Only in 8 quarters out of the total 71 quarters under study, the GDP growth was less than $4 \%$. 35 quarters had GDP growth rate more than $7 \%$. India seemed to be reaping the rewards of reforms that were made in the early 1990s. As a result, total trade in goods and services has leapt to $45 \%$ of GDP, from $17 \%$ in 1990 (MOSPI data). Moreover, liberalization has positive impact on GDP from two perspectives: it unleashes 
suppressed entrepreneurial energy and improves the allocation of resources. One of the factors that may have led to an increase in labour productivity is the employment of better quality machines by firms coupled with huge investments in technology, research and development.

The GDP growth rate differs during the different phases of the business cycle, provoking an immediate response from monetary authorities.

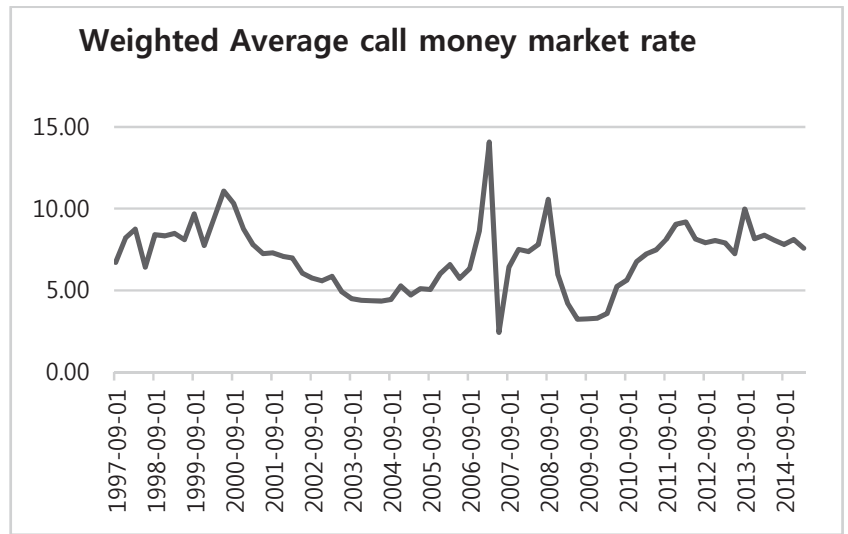

Figure 3: Trend of weighted average call money market rate during multiple indicator regime

A time series plot of weighted average call money market rates is depicted in Figure 3 above. Call money market rate in India have shown many ups and downs reflecting the prevailing domestic and global economic or financial conditions. With the average rate being $6.98 \%$, it reached maximum rate of $14.07 \%$ in 2006 and minimum rate of $2.42 \%$ in 2007. Out of the 71 quarters, 48 quarters had the rate more than 6\%, while 24 quarters had it over $8 \%$. From 2000 it showed a declining trend till 2006. It rose sharply and plunged in 2006 and 2007 respectively. After 2009 it started showing an increasing trend again. Higher liquidity during 2009 and 2010 saw rates dipping significantly and tightening of liquidity saw rates rising in 2011 and 2012. This shows the inherent volatility in the rates as they fluctuated widely as per the demand and supply conditions of the funds in the money market. RBI has over the years taken many structural measures and instrument-specific measures like transformation of call money market into pure interbank market, etc. to develop the money market.

\subsection{Results of the SVAR Model}

Since the aim of the present study is to see the impact of changes in monetary policy on inflation and growth in India, the below shown graphs of the impulse response function makes it clearer. We will also explore the effect of shocks in GDP growth on inflation.

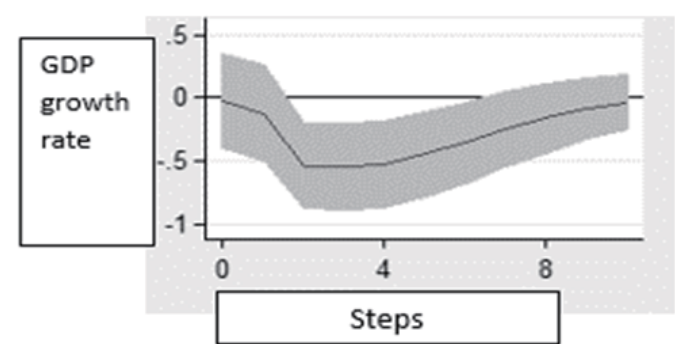

Figure 4: SVAR Impulse Response of Call Money Market Rate on GDP growth rate

The impulse response function (Figure 4) shows that an increase in the policy rate by $1 \%$ leads to a fall in GDP growth rate by nearly $0.5 \%$. The fall is gradual in the first quarter and steep in the second quarter. The fall in the GDP growth stabilizes in the third quarter and starts converging towards the base line from the start of 5 th quarter. Overall impact of the fall persists for 4 quarters. These results seem largely in line with the findings of Aleem (2010), Salunkhe and Patnaik (2017), Mohanty (2012) and some other studies that have found that monetary policy shocks impact output with a lag of about two quarters.

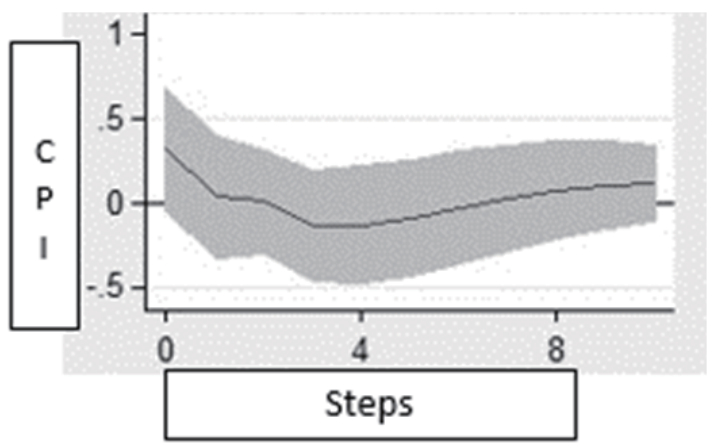

Figure 5: SVAR Impulse Response of Call Money Market Rate on $\mathrm{CPI}$

The impact of monetary policy shock on inflation (Figure 5) occurs with some lags after the GDP growth as most other studies have shown too. CPI inflation starts falling only after 2 quarters and the maximum impact is felt in the third quarter. The overall decline in CPI inflation continues for 3 quarters ahead. Salunkhe and Patnaik (2017) also find that the impact of a policy shock on inflation occurs after five months, with the maximum impact occurring in the sixth month. Since inflation expectations are a key determinant of the actual inflation outcome, and given the lags in monetary transmission, the Reserve Bank of India has been taking pre-emptive measures to keep inflation expectations stable. 
Our results regarding the impact of a policy rate shock on output on inflation broadly endorse the findings of Mishra, Montiel, and Sengupta (2016), Sengupta (2014), Mohanty (2012), Salunkhe and Patnaik (2017), Khundrakpam and Jain (2012) who find the interest rate channel as the most effective channel of monetary policy transmission in India. The efficacy of this channel has also significantly improved in the post-LAF period after 2000.

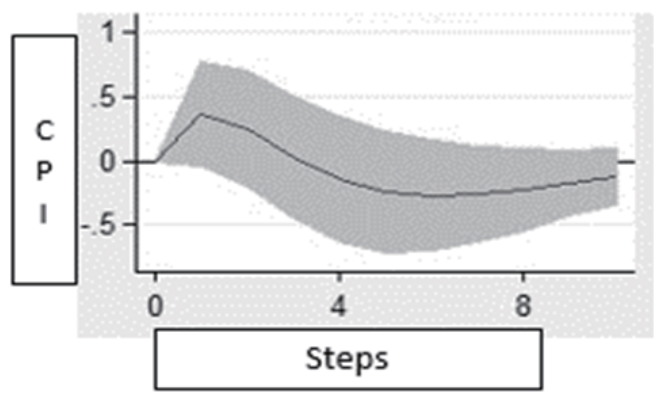

Figure 6: SVAR Impulse Response of GDP growth rate on CPI

A $1 \%$ rise in GDP growth rate leads to nearly $0.25 \%$ fall in CPI (Figure 6). The shock to the GDP growth rate (widening of the output gap) leads to a fall in inflation after three quarters. The peak impact is felt in the sixth quarter. The fall in inflation persists for several quarters ahead. What the central bank does today affects the economy around two to three quarters down the line, so the central bank should not take decisions based on recent data but the inflation forecast for six to nine months into the future.

\subsection{Inflation Targeting Regime Analysis}

After pursuing multiple indicator channel for monetary policy transmission, now $\mathrm{RBI}$ is shifting towards implementing an inflation targeting framework. As per this framework RBI remains answerable to the government if inflation goes above $6 \%$ or goes below $2 \%$ for three consecutive quarters. It is crucial that GDP growth should not take a hit in an attempt to control inflation: it is necessary to strike a fine balance between the two. How effective is the newly introduced inflation targeting regime in handling increasing global financial volatility, its linkages and its economic repercussions on India remains to be seen. It is noted that under this regime, inflation has averaged $3.9 \%$, just 10 basis points below the medium-term target that has been set by the government. It was close to target but volatile in this period, ranging from $6.1 \%$ in July 2016 to $1.4 \%$ in June 2017 . This volatility is partly explained by the transition to the new goods and services tax (GST) regime and the effect of higher house rent allowances for government employees on the rent component of the consumer price index.

Other complications have included the demonetisation shock, the gyrations in the global energy market, and the declining trend in food inflation since June 2016. The trend in core inflation which is calculated after the effects of volatile items such as food and fuel are removed from the headline inflation number, is a bit different. Average core inflation in this regime has been 100 basis points higher than $4 \%$. The other way to look at the issue is through global comparisons. India began the decade with significantly higher inflation than other countries of the world. Such comparison gives us some intuitive sense of the success of our monetary policy since all countries are otherwise subject to the same shocks from oil and food prices.

\section{Policy Implications and Conclusion}

Indian monetary authorities are equally concerned about inflation and growth when deciding the monetary policy. The monetary policy in India has a significant impact on output and inflation in the short-to-medium-run. After the policy shock, the fall in the output growth rate is of greater magnitude than the fall in inflation. Hence, attempts to control inflation by pursuing tight monetary policy hurt the growth process in India. The inflation gap with the rest of the world has now narrowed, making India less of an inflation outlier than before. It would indeed be an interesting endeavour to take this research further to know how different is the impact of shocks to repo rate on GDP growth and inflation under this new regime.

\section{References}

Aleem, A. (2010). Transmission Mechanism of Monetary Policy in India. Journal of Asian Economics, 21,186-197.

Al-Mashat, R. (2003). Monetary Policy Transmission in India: Selected Issues and Statistical Appendix (Country Report No. 03/261). Washington, DC: International Monetary Fund.

Bernanke, B. S., \& Blinder, A. S. (1992). The Federal Funds Rate and the Channels of Monetary Policy Transmission. American Economic Review, 82, 910-921.

Bernanke, B., \& Gertler, M. (1995). Inside the Black Box: The Credit Channel of Monetary Policy Transmission. The Journal of Economic Perspectives, 9(4), 27-48. 
Bhattacharya, R., Ila, P., \& Shah, A. (2011). Monetary Policy Transmission in an Emerging Market Setting (Working Paper WP/11/5). Washington, DC: International Monetary Fund.

Boivin, J., \& Giannoni, M. (2008). Global Forces and Monetary Policy Effectiveness (NBER Working Paper 13736)

Boivin, J., Kiley, M. T., \& Mishkin, F. S. (2010). How has the Monetary Transmission Mechanism Evolved Over Time? (NBER Working Paper 15879).

Bredin, D., \& OReilly, G. (2001). An Analysis of the Transmission Mechanism of Monetary Policy in Ireland (Research Technical Papers 1/RT/01). Dublin, Ireland: Central Bank of Ireland.

Das, S. (2015). Monetary Policy in India: Transmission to Bank Interest Rates (IMF Working Paper No. 15/129).

Endut, N, Morley, J., \& Tien, P.-L. (2018). The Changing Transmission Mechanism of US Monetary Policy. Empirical Economics, 54(3), 959-987.

Fisher, I., \& Brown, H. G. (1911). The purchasing power of money: Its determination and relation to credit, interest and crises. New York, NY: The Macmillan Company.

Friedman, M. (1956). The quantity theory of money - a restatement, In Studies in the quantity theory of money. Chicago, IL: University of Chicago Press.

Fujiwara, I. (2004). Output Composition of the Monetary Policy Transmission Mechanism in Japan. Topics in Macroeconomics, 4(1). Retrieved June 25, 2019 from: https://keio.pure.elsevier.com/en/publications/outputcomposition-of-the-monetary-policy-transmissionmechanism-

Ghazanchyan, M. (2014). Unraveling the Monetary Policy Transmission Mechanism in Sri Lanka (IMF Working Paper 2014/190).

He, L. T. (2017). Emphasis and Effectiveness of Monetary Policy of the Fed: A Historical Comparative Analysis 1871-2013. International Journal of Monetary Economics and Finance, 10(9), 47-67.

Hume, D. (1985). Essays: moral, political and literary (ed.). Miller, Indianapolis: Liberty Fund.

Jannsen, N., Wolters, M., \& Potjagaio, G. (2015). Monetary Policy during Financial Crises: Is the Transmission Mechanism Impaired? (Kiel Working Papers, No 2005).

Kapur, M., \& Behera, H. (2012). Monetary Transmission Mechanism in India: A Quarterly Model (RBI Working Paper No. 9).

Keynes, J. M. (1932). A Tract on Monetary Reform. London, England: Macmillan.

Khundrakpam, J. (2012). Estimating Impacts of Monetary Policy on Aggregate Demand in India (RBI Working Paper Series WPS DEPR 18/2012).
Khundrakpam, J., \& Jain, R. (2012). Monetary Policy Transmission in India: A Peep inside the Black Box (RBI Working Paper Series WPS DEPR 11/2012).

Khundrakpam, J. K. (2011). Credit Channel of Monetary Transmission in India - How Effective and Long is the Lag? (RBI Working Paper No. 20).

Lerskullawat, A. (2018). Financial Development and the Lending Channel of Monetary Policy Transmission: Evidence from Thailand. International Journal of Monetary Economics and Finance, 11(3), 224-234.

Mallick, S. (2009). Macroeconomic Shocks, Monetary Policy and Implicit Exchange Rate Targeting in India. London, England: Queen Mary University of London.

Mishra, P., \& Montiel, P. J. (2013). How Effective Is Monetary Transmission in Developing Countries? A Survey of the Empirical Evidence. Economic Systems, 37(2), 187-216.

Mishra, P., Montiel, P. J., \& Spilimbergo, A. (2012). Monetary Transmission in Low-Income Countries. IMF Economic Review, 60(2), 270-302

Mishra, P., Montiel, P. J., \& Sengupta, R. (2016). Monetary Transmission in Developing Countries: Evidence from India (IMF Working Paper WP/16/167).

Mohan, R. (2007). Monetary Policy Transmission in India. Paper presented at the Deputy Governors Meeting on Transmission Mechanism of Monetary Policy in Emerging Market Economies - What is New? Basel, Switzerland: Bank of International Settlements.

Mohanty, D. (2012). Evidence on Interest Rate Channel of Monetary Policy Transmission in India (RBI Working Paper No. 6).

Moreira, R. R., Chaiboonsri, C., \& Chaitip, P. (2014). Analysing Monetary Policy's Transmission Mechanisms through Effective and Expected Interest Rates: An Application of MS-models, Bayesian VAR and Cointegration Approaches for Brazil. International Journal of Monetary Economics and Finance, 7(1), 1-12.

Pandit, B. L., Mittal, A., Roy, M., \& Ghosh, S. (2006). Transmission of Monetary Policy and the Bank Lending Channel: Analysis and Evidence for India (DRG Study No.25). Mumbai, India: Reserve Bank of India.

Prabu, E. A., \& Ray, P. (2019). Monetary Policy Transmissions in Financial Markets: Evidences from India. Economic and Political Weekly, 54(13), 68-74.

Ramlogan, C. (2004). The Transmission Mechanism of Monetary Policy: Evidence from the Caribbean. Journal of Economic Studies, 31(5), 435-447.

Romer, C., \& Romer, D. (1990). New Evidence on the Monetary Transmission Mechanism (Brookings Papers on Economic Activity). 
Salunkhe, B., \& Patnaik, A. (2017). The Impact of Monetary Policy on Output and Inflation in India: A Frequency Domain Analysis. Economic Annals, LXII 212, 113-154.

Sengupta, N. (2014). Changes in Transmission Channels of Monetary Policy in India. Economic and Political Weekly, $X$ LIX (49), 62-71.

Silva, M. J. D. M., Brasil, G. H., \& Moreira, R. R. (2016). Dynamic relations of the Inertia of Monetary Policy: Application to the Brazilian Case by a Kalman Approach. International Journal of Monetary Economics and Finance, 9(1), 1-24.

Sims, C. (1980). Macroeconomics and Reality. Econometrica, 48(1), 1-48.
Singh, B. (2011). How Asymmetric is the Monetary Policy Transmission to Financial Markets in India? RBI Occasional Papers, 32(2). Retrieved from https://m.rbi.org.in/scripts/bs_viewcontent.aspx?ld=2594

Singh, K., \& Kalirajan, K. (2007). Monetary transmission in post-reform India: An evaluation. Journal of the Asia Pacific Economy, 12(2), 158-187.

Vo, X. V., \& Nguyen, P. C. (2017). Monetary Policy Transmission in Vietnam: Evidence from a VAR Approach. Australian Economic Papers, 56, 27-38.

Wulandari, R. (2012). Do Credit Channel and Interest Rate Channel Play Important Role in Monetary Transmission in Indonesia? A Structural Vector Autoregression Model. Procedia- Social and Behavioural Sciences, 65, 557-563. 